\title{
Por uma educação a favor da práxis: ação, educação e cultura
}

\author{
For an education in favor of praxis: action, education and culture \\ Por una educación a favor de la praxis: acción, educación y cultura
}

Recebido: 18/01/2021 | Revisado: 21/01/2021 | Aceito: 23/01/2021 | Publicado: 30/01/2021

\author{
Lucia Gomes Serpa \\ ORCID: https://orcid.org/0000-0001-7463-9868 \\ Universidade Federal da Paraíba, Brasil \\ E-mail: luciaserpa.lap@gmail.com \\ Charliton José dos Santos Machado \\ ORCID: https://orcid.org/0000-0002-4768-8725 \\ Universidade Federal da Paraíba, Brasil \\ E-mail: charlitonlara@yahoo.com.br \\ Gabriel Alves do Nascimento \\ ORCID: https://orcid.org/0000-0003-0190-9235 \\ Universidade Federal da Paraíba, Brasil \\ E-mail: gabrielalves.educ@gmail.com \\ Aline Rodrigues de Almeida \\ ORCID: https://orcid.org/0000-0002-0152-3941 \\ Universidade Federal da Paraíba, Brasil \\ E-mail: aline.ralmeidas2@gmail.com
}

\begin{abstract}
Resumo
O presente artigo traz algmas reflexões acerca da educação e da cultura, tendo como parâmetro a perspectiva crítica freireana. As reflexões que ora apresentamos giram em torno da coerência entre o dito e o feito (Práxis). Nosso objetivo é o de: Analisar as categorias freireanas Educação; Conscientização; Cultura e Cultura Popular atravessados pelo conceito de Práxis percebendo o pensar e o agir como práticas indissociaveis para os educadores de nosso tempo. A metodologia utilizada é a da revisão bibliográfica com ênfase na revisão narrativa de base qualitativa. Portanto, partimos do princípio de que a educação é um ato político, mas, também, de que todo ato político crítico necessita realizar reflexões acerca da realidade concreta, visto que esta não está dada de forma explícita. É preciso desvelá-la. Textos como este que aqui expomos visam estimular o processo de conscientização, posto que este só se concretiza na práxis. A temática que apresentamos é atual e necessária, conectando tempos que por vezes parecem longinquos, mas que na conjuntura atual se fazem pertinentes. Os resultados apontam que o revisitar das obras de Paulo Freire estão cada vez mais atuais e são possiveis de serem implementados na vida cotidiana do educador, defendemos ainda que Freire ao desenvolver o conceito de Práxis contribui fortemente para elucidar a lacuna entre o pensar e o agir e assim reconhecer a nossa condição de opressor/oprimido para que em algum momento possamos superá-la.
\end{abstract}

Palavras-chave: Ação; Educação; Cultura; Práxis.

\begin{abstract}
This article brings some reflections about education and culture, taking as a parameter Freire's critical perspective. The reflections that we present revolve around the coherence between what is said and what is done (Praxis). Our goal is to: analyze the Freire's Education categories; Awareness; Culture and Popular Culture crossed by the concept of Praxis, perceiving thinking and acting as inseparable practices for the educators of our time. The methodology utilized is bibliographic review with emphasis on qualitative based narrative review. Therefore, we start from the principle that education is a political act, but also that every critical political act needs to reflect on concrete reality, since it is not given explicitly. It needs to be unveiled. Texts like the one we have here aim to stimulate the awareness process, since this only takes place in praxis. The theme that we present is current and necessary, connecting times that sometimes seem remote, but that in the current situation are pertinent. The results show that the revisiting the works of Paulo Freire is more and more current and is possible to be implemented in the daily life of the educator, we also defend that Freire when developing the concept of Praxis contributes strongly to elucidate the gap between thinking and acting and thus recognize our condition of oppressor / oppressed so that at some point we can overcome it.
\end{abstract}

Keywords: Action; Education; Culture; Práxis.

\section{Resumen}

Este artículo trae algunas reflexiones sobre educación y cultura, tomando como parámetro la perspectiva crítica de Freire. Las reflexiones que presentamos ahora giran en torno a la coherencia entre lo que se dice y lo que se hace (Praxis). Nuestro objetivo es: Analizar las categorías de Educación de Freire; Conciencia; Cultura y Cultura Popular atravesadas por el concepto de Praxis, percibiendo el pensar y el actuar como prácticas inseparables de los educadores 
de nuestro tiempo. La metodología utilizada es la de revisión bibliográfica con énfasis en la revisión narrativa de base cualitativa. Por tanto, partimos del principio de que la educación es un acto político, pero también de que todo acto político crítico necesita reflexionar sobre la realidad concreta, ya que no sucede explícitamente. Necesita ser desvelado. Textos como el que aquí se presentan tienen como objetivo estimular el proceso de conciencia, ya que solo tiene lugar en la praxis. La temática que presentamos es actual y necesaria, conectando tiempos que a veces parecen lejanos, pero que en la situación actual son pertinentes. Los resultados muestran que revisitar las obras de Paulo Freire son cada vez más actuales y posibles de ser implementadas en la vida diaria del educador, también defendemos que Freire al desarrollar el concepto de Praxis contribuye fuertemente a dilucidar la brecha entre pensar y actuar y así reconocer nuestra condición de opresor/oprimido para que en algún momento podamos superarla.

Palabras clave: Acción; Educación; Cultura; Práxis.

\section{Introdução}

Este trabalho inicia a partir de reflexões sobre algumas atitudes humanas que não deixam de assombrar olhos observadores. Muito é falado, escrito e discutido sobre a sociedade atual, sobre seus infortúnios, sua violência progressiva, o achatamento e inversão de valores, sobre a crise que perpassa todas as áreas - do micro ao macro, do indivíduo ao sistema instituído e legalizado por um Estado. E é a partir de 2020 com o avanço da pandemia do novo Corona Vírus (Sars-Cov 2) deixando mais de duzentas mil pessoas mortas é que essa crise se acentua. Acreditamos estar vivenciando não apenas uma crise sanitária, mas uma crise de valores humanos e institucionais, de crescentes avanços dos setores neoliberais e de enriquecimento da população mais rica do mundo.

Dito isto, é preciso pensar no papel da educação e dos educadores (Lovato et al, 2020) na urgência do revisitar de obras clássicas e necessária para irmos ao encontro a um horizonte mais esperançoso (Freire, 2015). Não podemos aguardar que as soluções cheguem pelos setores dominantes, é urgente que os educadores se organizem para denunciar esse processo de desumanização institucionalizado, anunciando assim um outro paradigma possível de conceber o trabalho pedagógico dentro e fora da sala de aula. O ano de 2021 inicia marcado pelo Corona Vírus, mas também anuncia um mundo de sonhos possíveis, o centenário de Paulo Freire é um prenúncio de inéditos viáveis (Freire, 2015) capazes de acreditar no mundo e nas mulheres e nos homens de nosso tempo. Portanto, partiremos de algumas de suas obras, revisitando-as, entendendo ser imprescindível e urgente anunciar à possibilidade de um mundo diferente, mais humano e possível.

Partindo deste cenário o objetivo deste artigo é: Analisar as categorias freireanas Educação; Conscientização; Cultura e Cultura Popular atravessados pelo conceito de Práxis percebendo o pensar e o agir como práticas indissociáveis para os educadores de nosso tempo. Ora, as discussões se fazem necessárias assim como as ideologias, pois, podem tornar-se realidade. A sociedade necessita que novas ideias, ou ideias já existentes e que nunca obtiveram forma, venham a se constituir em novas colunas que alicercem uma nova visão de mundo.

A palavra nova foi utilizada repetidamente para transmitir a urgência de que a sociedade seja transformada. Mas ela é feita por indivíduos. Indivíduos que se enredaram em suas próprias malhas, teias, leis, mentiras, corrupções, desejos, instintos, equívocos e que "desapareceram” em nome de um sistema dominante. Sobre essa questão, afirmam Boff \& Muraro (2002) “A humanidade está passando inegavelmente por uma crise que atinge os fundamentos da sua subsistência na Terra. Em momentos assim sentimo-nos urgidos a somar forças e a identificar fontes de inspiração que nos possam salvar”. (p.17).

Sim, passamos por uma crise. Crise dos sentidos que já não sabem olhar nem tampouco ouvir. Crise de valores, de paradigmas, de sistemas econômicos e políticos, de organização social e de crenças. Mas não vamos ficar apenas na constatação pessimista e acreditar que já não há mais o que fazer, assumindo uma posição passiva e cúmplice da situação vigente. Diante dessa complexidade, assevera Konder (1994):

Não podemos nos permitir uma postura contemplativa, de observadores resignados, diante desse quadro. Não podemos deixar que matrizes ideológicas conservadoras induzam-nos à conclusão pessimista e desmobilizadora que 'não há nada a fazer'. Estaríamos acumpliciando-nos com a monstruosidade se achássemos que os atuais níveis de 
violência e destrutividade são 'naturais”. (p.13)

O referido autor coloca a violência como uma "dimensão ineliminável da existência humana" e que não poderíamos "extingui-la". Afirma que essa violência está entranhada na esfera política e na vida privada, "na intimidade dos sentimentos, no plano das relações amorosas, no espaço de formação da sensibilidade e do gosto". (Konder, 1994, p.11-12).

As relações de poder são levadas ao desejo, ao sexo, na relação entre homens e mulheres, na relação entre indivíduos. Acredita o autor que precisamos conhecer o "como, historicamente, chegamos a ela". Refere-se à situação de uma crise ética da nossa sociedade. E, por isso, deveríamos olhar mais profundamente a história dos dois últimos séculos, revisitando "espíritos inquietos", como no caso de sua obra, A vida de Flora Tristan, a brava mulher francesa do século XIX que foi esquecida pela parcela da humanidade que escreve uma história dita "oficial". (Ibidem, p.13-14).

Apenas na segunda metade do século XX esta figura notável é trazida com mais ênfase a ocupar um lugar merecido na historiografia relacionada com o socialismo e ao feminismo, ainda que apenas em poucos países mais ligados à sua vida, como França, Inglaterra e Peru.

Nesse sentido, Flora Tristan é um exemplo bastante pertinente para este trabalho. Ela foi escritora, uma espécie de cronista de sua época, foi uma mulher sofrida pela situação econômica que possuía, pela violência do marido, pelas leis francesas que não admitiam o divórcio e pelas mazelas da sociedade, na qual ela se colocou como uma crítica eloqüente e uma ativista determinada. Pois, aí encontramos um ponto nevrálgico para a defesa de um ponto de vista. Se não basta sermos observadores passivos e niilistas da situação vigente é importante que a ação seja coerente com o discurso. Ou que, em verdade, aconteça a ação.

Se Konder (1994) escreve e resgata a vida de Flora Tristan para os leitores brasileiros e essa é a forma na qual ele tem acesso para 'fazer a sua parte', assim como inúmeros intelectuais o fazem, descrevendo problemas, em alguns momentos apontando soluções, tornando possível uma discussão que possa se alargar por todos os meandros da sociedade, como tudo isso pode vir a se tornar energia transformadora dessa mesma sociedade?

Foi utilizada a expressão energia transformadora para indicar uma força propulsora que possa gerar a tão necessária transformação, pois, à luz das ideias gramscianas, as quais nos orientam que as estruturas sociais e políticas não precisam ser destruídas para que uma nova ordem nasça, mas, sim, reformadas. E, nesse processo, os intelectuais orgânicos teriam uma importância vital, pois são aqueles que pensam e agem.

Todo grupo social, nascendo no terreno originário de uma função essencial no mundo da produção econômica, cria para si, ao mesmo tempo, organicamente, uma ou mais camadas de intelectuais que lhe dão homogeneidade e consciência própria da função, não apenas no campo econômico, mas também no social e político (Gramsci, 2004, p.15).

O saber está relacionado e comprometido com a prática. Prática essa que está comprometida também com a cultura na qual o indivíduo está inserido (do grupo da qual faz parte) e com as necessidades socioeconômicas desse grupo. Mas para o aparecimento e consolidação desse ideal de organicidade entre teoria e prática é necessário que adentremos uma questão fundamental para o caminho traçado por uma sociedade: a educação.

\section{Metodologia}

A andarilhagem metodológica que percorremos tem suas bases na Pesquisa de Revisão Bibliográfica, em especial na Revisão Narrativa de base qualitativa (Bogdan \& Biklen, 1994) revisitando algumas obras de Paulo Freire (1970; 1979; 1996; 2015) para que neste ano de 2021 em seu centenário, possamos articular novas maneiras de conceber o trabalho pedagógico 
dentro e fora da sala de aula. As obras utilizadas neste artigo são as primeiras edições, para que possamos fazer uma análise a luz do tempo e do espaço vivido por Freire, pois a centralidade de nosso objeto é o de analisar a partir da perspectiva da Revisão Narrativa os escritos de Freire no tempo em que foi publicado, em uma conjuntura específica. Para que possamos visualizar a urgência e a emergência deste autor e de seus escritos atualmente.

Esta pesquisa está alicerçada no método qualitativo, pois comungamos do pensamento de Pereira et al. (2018) ao afirmar que "Os métodos qualitativos são aqueles nos quais é importante a interpretação por parte do pesquisador com suas opiniões sobre o fenômeno em estudo". (p.67). Dessa forma, lançamos mão da interpretação dos conceitos freireanos para estabelecermos um outro modo de desenvolver a prática educativa dos educadores. Utilizaremos as seguintes categoriais freireanas de análise: Educação; Conscientização; Cultura e Cultura Popular. Para irmos ao encontro do conceito de Práxis, estabelecendo uma profunda relação entre a lacuna do pensar e do agir.

Portanto, partimos de problemas reais para irmos ao encontro das categorias e conceitos freireanos, defendendo-os como atuais e necessários à transgressão da condição de oprimido/opressor, estabelecendo uma nova maneira de enxergar o outro e o mundo, utilizando a Práxis como centralidade de todo e qualquer processo educativo.

\section{Educação e Conscientização}

Inicialmente, gostaríamos de justificar a escolha por Paulo Freire. Por que esse pensador e ativista educacional e não outro? Porque Freire foi um intelectual extremamente coerente ao longo de sua vida. Revisitou suas obras, assumiu erros, mudou opiniões próprias e escreveu, como disse Scocuglia (2003), "uma obra em constante movimento de reelaboração e de reconstrução" (p.53). Suas obras continuam vivas e repletas de significados nos dias atuais, e é partindo de seus escritos e de suas ideias para o mundo que pretendemos desenvolver as próximas linhas deste artigo.

O autor está referenciando uma tríade iniciada com as obras: Educação e atualidade brasileira, Educação como prática da liberdade e complementada por Pedagogia do Oprimido. Podemos notar essa reconstrução e uma renovação do olhar em toda a obra freireana, haja vista que traz fortemente a ideia de que a educação é um ato político e insiste na necessidade da conscientização para a transformação da sociedade. Sobre essa questão assevera Freire:

O mesmo equívoco que caí, no começo de minhas atividades, venho surpreendendo, na minha experiência atual, às vezes mais acentuado, em pedagogos que não veem as dimensões políticas de sua prática pedagógica. Daí que falem de uma 'conscientização estritamente pedagógica'. Uma conscientização que se daria na intimidade de seus seminários, mais ou menos acética, que não teria nada a ver com nenhum compromisso de ordem política. Uma tal separação entre educação e política, ingênua ou astutamente feita, enfatizemos, não é apenas irreal, mas perigosa (Freire,1979, p.146).

Então partimos do princípio de que a educação é um ato político. Também acreditamos que nossos atos acabam adquirindo um caráter político (Mattos et al, 2020). Podemos lembrar de alguns pensadores de diversas áreas a exemplo de: Freud, Balzac, Genet, Foucault e dos estudiosos(as) que abordam a questão de gênero, no tocante às relações de poder que estão incutidas nas nossas ações e relações cotidianas, reproduzindo, assim, uma situação dominante/dominado. A conscientização adentra, assim, no contexto socioeducativo como prática política. Se refletirmos na própria palavra conscientização, observamos a presença de três elementos: com; ciência e ação. Ciência traz, essencialmente, a ideia de saber, assim chegamos a soma de com; saber e ação. É um pequenino e simples jogo de palavras, mas que descortina a essência de um significado. Então: com o saber conduzo-me. Há aqui uma ideia de processo, de movimento, pois a partir de um aprendizado eu me coloco em ação.

Vivemos em uma sociedade que demanda uma interação entre os indivíduos e esses com os princípios que regem o grupo onde estão inseridos. O nosso aprendizado se dá, normalmente, no coletivo - a família, a escola, a comunidade, a cidade, 
Estado, pais, continente, mundo - pois somos cidadãos do mundo, algo afirmado de forma consistente por Freire. É preciso que tenhamos consciência desse fato e que também somos sujeitos da história e não vítima, como pergunta o personagem principal da obra David Copperfield, de Charles Dickens: "Serei herói de minha própria história ou para sempre sua vítima?". Temos então a noção de espaço (o mundo) e tempo (a história). Essa noção nos insere em uma materialidade onde somos objetivados cotidianamente.

Fazemos parte de uma sociedade como seus cidadãos. Mas a ideia de cidadania já contém uma relação de subjetividade. Santos (1995) fala de uma complexidade entre cidadania e subjetividade:

Para além das ideias de autonomia e de liberdade, a subjetividade envolve as ideias de auto reflexividade e de auto responsabilidade, a materialidade de um corpo (real ou fictício, no caso da subjetividade jurídica das 'pessoas coletivas'), e as particularidades potencialmente infinitas que conferem o cunho próprio a personalidade. Ao consistir em direitos e deveres, a cidadania enriquece a subjetividade e abre-lhe novos horizontes de autorrealização, mas, por outro lado, ao fazê-lo por via de direitos e deveres gerais e abstratos que reduzem a individualidade ao que nela há de universal, transforma os sujeitos em unidades iguais e intercambiáveis no interior de administrações burocráticas públicas e privadas, receptáculos passivos de estratégias de produção, enquanto força de trabalho, de estratégias, de consumo, enquanto consumidores, e de estratégias de dominação, enquanto cidadãos da democracia de massas. (p.240)

Encontramos nessa afirmação, a subjetividade existente no micro (indivíduo enquanto corpo e personalidade, no individual e no coletivo) até o macro (Estado que legitima os meios de produção, as estratégias de consumo e de dominação). Retornamos à ideia de que nossos atos são políticos, pois estão interligados à rede de direitos e deveres que regem nossa cidadania.

A Estratégia de dominação subentende uma situação dominante/dominado ou opressor/oprimido. Esta é uma realidade que no campo da educação precisa ser conscientizada para, assim, haver uma transformação (novamente a ação no término da palavra). Ou seja, é preciso se reconhecer oprimido ou se reconhecer opressor para que essas relações sejam modificadas, que o oprimido conscientize-se de sua condição e rompa as amarras que lhes foram inculcadas, e que o opressor reconheça que a força - moral, física, psíquica e material exercida sobre outros seres humanos deverá ser cessada para que possamos reconfigurar um novo modelo de sociedade, não mais orientadas por classes, mas sobretudo orientadas pela humanidade e solidariedade.

A práxis, porém, é a reflexão e ação dos homens sobre o mundo para transformá-lo. Sem ela, é impossível a superação da condição opressor-oprimido. Desta forma, esta superação exige a inserção crítica dos oprimidos na realidade opressora, com que objetivando-a, simultaneamente atuam sobre ela (Freire, 1970, p.38).

Portanto, a tomada de consciência é um primeiro passo que demanda a inserção crítica e que nas palavras de Freire, só se concretiza na práxis. Concordamos, então, que a educação (a palavra ação novamente) não pode estar desvinculada da posição política. Não estamos falando de política partidária, mas do ato de existir como cidadãos do mundo de nos colocarmos frente a atos de desigualdade, de questionarmos as relações tóxicas e principalmente de reconhecermos como sujeitos que em determinado momento é oprimido e em outro poderá ser o opressor.

\section{Educação e Cultura}

Não estamos, neste trabalho, aprofundando questões pertinentes para o entendimento da situação atual que nos encontramos, como o capitalismo que gera uma cultura de exclusão, trazendo redefinições em relação à divisão de classes ou a importância dos movimentos sociais para o estabelecimento da ação transformadora da sociedade, tampouco adentraremos a questão de gênero que tão bem mostra a relação dominante/dominado em nossas relações pessoais. Estamos nos atentando a 
algumas considerações que nos levem a refletir sobre o papel do indivíduo na sociedade, e, em especial, a educação como um ato político e, o que veremos a seguir, a cultura como um conceito fundamental para o repensar a educação no mundo de hoje.

Vejamos agora como a educação está vivenciando o tempo presente, "numa época de globalização da economia e das comunicações, mas, também, numa época de acirramento das contradições inter e intrapovos e nações, época do ressurgimento do racismo e de certo triunfo do individualismo". (Gadotti, 2000, p.41).

$\mathrm{O}$ autor introduz a discussão do papel de uma escola com muitas culturas, trazendo o conceito de identidade como um desafio global. Não é mais possível que se utilize a educação como uma forma onde todos sairão iguais, como um processo automatizado de produção. São muitos os autores que falam sobre diversidade, colocando a necessidade de se respeitar as diferenças, as identidades de cada grupo. Mas conseguiremos fazer com que novos modelos sejam legalizados por um Estado, dito, democrático? Sobre essa questão afirma Candau (2000):

Me atreveria a afirmar que é esta perspectiva que está mudando, pelo menos em grupos significativos de nossas sociedades, especialmente aqueles aos que é negado o acesso pleno à cidadania e à democracia. Suas vozes se fazem ouvir, surda, clara ou violentamente. E a sociedade começa a se preocupar pela construção de dinâmicas sociais mais inclusivas e participativas, em muitos casos orientados exclusivamente para minimizar tensões e conflitos. Certamente o que já não é possível é negar está problemática. (p.47)

A autora não está falando que essas vozes chegarão a mudar os modelos existentes até serem instituídas por um Estado, mas que há um crescimento significativo de seu alcance. Sabemos de práticas estabelecidas com sucesso por escolas particulares de outros estados, algumas prefeituras, organizações não governamentais (ONGs), movimentos sociais, como o MST, o trabalho que o Instituto Paulo Freire desenvolve, mas, infelizmente, soam como experiências e não como uma mobilização conjunta para a transformação dos modelos educacionais vigentes neste vasto país de tanta diversidade que é o Brasil.

Mas é claro que tudo tem que começar de alguma forma e o que Candau (2000), afirma, traz esperança. Todas estas experiências são louváveis e que possam ser sementes que frutifiquem em cada recanto dessa terra, mas a morosidade de uma máquina burocrática chamada governo impede que experiências renovadoras se alastrem, pois o que fariam com tantos cidadãos conscientes? Como manteriam a hegemonia de uma classe dominante? Sabemos que o poder é um ato político capaz de dar voz a alguns e silenciar outros grupos. Aqui, nos cabe questionar essas relações e essa hegemonia, acreditamos que as experiencias de micro espaços, de instituições que na primeira vista parecem isoladas possam dialogar entre si, possam organizar estrategicamente um plano de educação pautado na práxis utilizando como cenário principal a solidariedade.

Em um trabalho realizado por uma ONG nas cidades paraibanas: Cabedelo e João Pessoa, em 2003, com um grupo de adolescentes de 13 a 19 anos, de comunidades de baixa renda, foi levantado que a grande maioria (95\%) não faz distinção entre cidades do mundo, nem tampouco do próprio país. São Paulo era considerada uma cidade fora do Brasil. Eles não tinham noção nem de sua comunidade em relação à cidade da qual fazem parte. Grande parte nunca havia saído de seu bairro. Vale ressaltar que eles estudavam em escolas públicas e muitos trabalhavam em serviços informais para ajudar em casa. Esta é a realidade que vivemos ainda. Sobre essa realidade ressalta Candau (2000):

As nossas salas de aula, onde pretensamente se ensina e se aprende, deveriam ser espaços de lidar com o conhecimento sistematizado, construir significados, reforçar, questionar e construir interesses sociais, formas de poder, de vivências que tem necessariamente uma dimensão antropológica, política e cultural. (p.52)

É esta dimensão que queremos tocar com esse trabalho. Já vimos que a educação e a política estão juntas. Reuniríamos aqui as dimensões antropológicas e culturais, concordando com Laraia (1996) ao afirmar que: 
O modo de ver o mundo, as apreciações de ordem moral e valorativa, os diferentes comportamentos sociais e mesmo as posturas corporais são assim produtos de uma herança cultural, ou seja, o resultado da operação de uma determinada cultura [...]. Graças ao que foi dito acima, podemos entender o fato de que indivíduos de culturas diferentes podem ser facilmente identificados por uma série de características, tais como o modo de agir, vestir, caminhar, comer, sem mencionar a evidência das diferenças linguísticas, o fato de mais imediata observação empírica [...] Cada sistema cultural está sempre em mudança. Entender esta dinâmica é importante para atenuar o choque entre gerações e evitar comportamentos preconceituosos. Da mesma forma que é fundamental para a humanidade a compreensão das diferenças entre povos de culturas diferentes, é necessário saber entender as diferenças que ocorrem dentro do mesmo sistema. Este é o único procedimento que prepara o homem para enfrentar serenamente este constante e admirável mundo novo do porvir. (p.70)

Assim, qual o papel da educação para este mundo novo ser um mundo melhor? Entender as diferenças, aprender com elas. Construir uma escola que ensine as perguntas, como bem disse Alves (2003): “As respostas nos permitem andar sobre a terra firme. Mas somente as perguntas nos permitem entrar pelo mar desconhecido. (p.19)" Este mesmo autor diz que a primeira tarefa da educação é ensinar as crianças a serem elas mesmas e a segunda é ensinar a conviver. Conviver com o diferente.

Freire (1996) nos traz a Pedagogia da Autonomia, aquela que nos leva à liberdade. Liberdade de ser. Ser em uma sociedade planetária, intercultural. Conscientes como indivíduos, como cidadãos. Que lindo será quando lá chegarmos. O educador queria ver marchas espalhadas pelo país. Que homens e mulheres se unissem para gritar que estavam juntos por um mundo melhor. Pode soar utópico. Mas a realidade precisa ser transformada a partir de alguma chama, ideia, vontade, ou quem sabe, utopia. Assim, a relação entre identidade cultural e educação necessita ser equacionada compreendendo que:

Toda reflexão sobre educação e a cultura pode assim partir da ideia segundo a qual o que justifica fundamentalmente, e sempre, o empreendimento educativo é a responsabilidade de ter que transmitir e perpetuar a experiência humana considerada como cultura, isto é, não como a soma bruta (e aliás inimputável de tudo o que pode ser vivido, pensado, produzido pelos homens desde o começo dos tempos, mas como aquilo que, ao longo dos tempos, pôde aceder a uma existência 'pública', virtualmente comunicável e memorável, cristalizando-se nos saberes cumulativos e controláveis, nos sistemas ininteligíveis, nos instrumentos aperfeiçoáveis, nas obras admiráveis. Neste sentido pode-se dizer perfeitamente que a cultura é o conteúdo substancial da educação, sua fonte e justificação última: a educação não é nada fora da cultura e sem ela. Mas reciprocamente, dizer-se-á que é pela e na educação, através do trabalho paciente e continuamente recomeçado de uma 'tradição docente' que a cultura se transmite e se perpetua: a educação realiza a cultura como memória viva, reativação incessante e sempre ameaçada, fio precário e promessa necessária da continuidade humana (Forquim, 1993, p.13).

Contudo, não podemos esquecer que a educação "é, ao mesmo tempo, uma exigência do e para o processo de trabalho, bem como é, ela própria, um processo de trabalho”. (Saviani, 2012, p.11). De modo que, ao esclarecer que o ser humano necessita produzir continuamente sua própria existência, Saviani (2012) aponta que no processo de transformação da natureza, os seres humanos criam o mundo humano, e, portanto, o mundo da cultura.

\section{Cultura Popular}

Forquim (1993) destaca fortemente a inter-relação entre educação e cultura com a perspectiva de humanidade, com a experiência humana que precisa de continuidade. Essa ideia se coaduna com a busca de significação de cultura por parte de Fávero (1983), que coloca as propriedades da cultura como sendo histórica, social, pessoal e universal. Encontramos aí aspectos objetivos e subjetivos que caminham entrelaçados. O indivíduo, o que ele é (assim como os grupos sociais) com o que ele produz, cria - suas obras culturais.

Assim seria a cultura que investe no ser humano o sentido de humanidade, com significações e valores que realizam o homem no mundo. A consciência histórica do homem (do grupo, da nação, da época) seria expressa pela cultura. Encerra-se aqui a ideia que trouxemos no início deste trabalho da consciência do micro ao macro, no tempo e no espaço. Somos enquanto 
pessoalidade, enquanto grupo social, enquanto nação, enquanto universalidade histórica. Retornamos, assim, ao conceito de conscientização para introduzir a cultura popular. Em sintonia com a filosofia freireana diz Fávero (1983):

É popular a cultura que leva o homem assumir a sua posição de sujeito da própria criação cultural e de operário consciente do processo histórico em que se acha inserido [...] um movimento de cultura popular é um movimento para a libertação do homem. (p.23)

E, por isso, uma manifestação de cultura popular é do e com o povo e não para o povo. Todos os instrumentos para o trabalho de cultura popular - alfabetização, núcleos populares, artes plásticas, teatro, música, cinema, festas, publicações, etc., são meios de conscientização. Politização e organização do povo para Fávero (1983). Vemos aqui a arte que busca estimular processos de conscientização. É a valorização da arte do povo trazendo o desenvolvimento da consciência crítica e da comunicação, além de expandir a leitura do mundo (a percepção). Nesse sentido, segundo Martins (1983), a "cultura popular é o resultado de uma reforma introduzida na cultura brasileira [...] reforma de sentido revolucionário". (p.37) Há então o apontamento de uma saída.

A ação que falávamos anteriormente poderia advir da cultura popular. Pelo menos o alastramento de meios de conscientização que cheguem às massas: "a cultura popular só existe se comportar como uma força, de caráter cultural, que age com o objetivo de tornar consciente para as massas o sentido de sua situação histórica” (Martins, 1983, p.39).

Aí está uma das forças propulsoras que buscávamos para a efetiva transformação da sociedade. Quem sabe as marchas, saudadas por Freire, poderiam surgir das manifestações da cultura popular, tendo em vista a afirmação de Estevam (1983) “A cultura popular deve ser a expressão cultural da luta política das massas, entendendo-se por essa luta algo que é feito por homens concretos ao longo de suas vidas concretas” (p.41).

A cultura popular possui, assim, um fim político com um caráter de classe, para isso necessita de intelectuais orgânicos que possam lhe dar direção, pois o que ainda vemos amiúde é a classe dominante alimentando manifestações reproduzidas, mas nunca reprodutoras de atitudes revolucionárias. Entretanto:

Seria uma ilusão pensar que os frutos de uma tal atividade virão imediatamente. Nem têm essa visão oportunista os homens da cultura popular. Estão eles conscientes da complexidade do fenômeno cultural e, por isso mesmo, sabem que só o trabalho contínuo e demorado poderá conduzir a resultados satisfatórios. E, porque o sabem, não querem perder tempo. (Gullar,1983, p.55).

Mas já não se perdeu tempo em demasia? Talvez, mas os processos de resistências são históricos e inconclusos, seja por meio da resistência cultural, a exemplo da cultura quilombola, indígena, cigana, rural ou periférica, seja por meio das revoltas e movimentos populares e de massa.

\section{Considerações Finais}

Muitos são aqueles que estão preocupados com o futuro. A sociedade capitalista se configura a partir de instâncias excludentes e violentas, que se reproduzem até nas relações íntimas, onde o poder necessita ser afirmado trabalhando sempre com a dicotomia entre opressor/oprimido. Mas apesar das preocupações e expressões existentes em relação à necessidade de uma transformação da sociedade, o que vemos são experiências muitas vezes isoladas e sem a força política para empreender tal movimento.

É necessário consciência de cada indivíduo de seu lugar de cidadão, de sua comunidade, classe, nação, mundo, planeta, universo. Mas essa consciência pede uma ação. A história é feita por homens, mulheres, idosos, crianças, negros, indígenas, pessoas com deficiências, LGBTQI+. O mundo é feito de diversidade. São culturas diferentes que podem e devem 
se unir, pois é a partir dessa interação que aprendemos e 'somos’ enquanto humanidade, enquanto seres históricos.

Para tanto, que sejamos heróis/heroínas de nossas histórias. Que a consciência de que somos seres políticos nos leve à ação e que a educação possa ser utilizada com o propósito de abertura e não de fechamento de abertura de visão de mundo. Acreditamos que existem diversas formas de agir. Enquanto alguns escrevem, outros falam, ensinam, aprendem, marcham, gritam, sonham e querem construir seu sonho. O movimento começa em cada sujeito histórico, cada um fazendo a sua parte.

A nossa contribuição neste escrito está imersa na leitura e na releitura de obras clássicas que tratou de abordar as categorias: Educação; Conscientização; Cultura e Cultura Popular, afirmando que a luta de classes continua a existir e continuará enquanto o capitalismo persistir em centrar esforços no acúmulo de riqueza para alguns e de acumulo de pobreza para muitos. Dessa forma, acreditamos que refletir sobre a coerência entre o fazer e o dizer em todas as instancias da vida cotidiana é uma tarefa atual, necessária e extremamente importante.

Este artigo poderá servir como ponto de partida ou de chegada para pesquisadores da Educação e das Ciências Humanas que se debruçam nas obras de Paulo Freire e em suas categorias analíticas, como também aqueles que pretendem conhecer a Práxis freireana e, principalmente, a todos os professores e professoras que promovem a Práxis em sua vida cotidiana ou que pretendem utilizá-la.

Portanto nosso escrito contribui para destacar a emergência de revisitar autores como Freire para permanecermos reconhecendo a nossa condição humana de oprimido e opressor para que possamos assim superá-la. A lacuna entre o que escrevemos, sabemos, dizemos e agimos, deverá ser superada. Quando começarmos a romper essa barreira e quem sabe encontraremos a força para participar da construção de uma sociedade mais justa e, consequentemente, de um mundo melhor.

\section{Referências}

Alves, R. (2003). Conversas sobre educação: Editora Verus.

Bogdan, R. C., \& Biklen, S. K. (1999) Investigação qualitativa em educação: Uma introdução à teoria e aos métodos. Tradução de Maria João Alvarez, Sara Bahia dos Santos e Telmo Mourinho Baptista: Porto. (Coleção Ciência da Educação).

Candau, V. M. (2000). Interculturalidade e educação escolar. In: Candau, V. M. (Org). Reinventar a escola. (4a ed.), Vozes.

Fávero, O. (1983). AP/Cultura Popular. In: Fávero, O. (org.) AP/ Cultura Popular. In: Cultura Popular e a Educação Popular: memória dos anos 60: Edições Graal.

Forquim, J. C. (1993). Escola e cultura: as bases sociais epistemológicas do conhecimento escolar. Tradução de Guacira Lopes Louro: Artes Médicas.

Freire, P. (1970). Pedagogia do oprimido: Paz e Terra.

Freire, P. (1979). Educação e mudança: Paz e Terra.

Freire, P. (1996). Pedagogia da autonomia: Paz e Terra.

Freire, P. (2015). Pedagogia da Esperança: Um reencontro com a Pedagogia do Oprimido: Paz e Terra.

Gadotti, M. (2000). Perspectivas atuais da educação: Artmed.

Gramsci, A. (2004). Cadernos do cárcere. Vol. II. Tradução de Carlos Nelson Coutinho. (3a ed.):Civilização Brasileira.

Gullar, F. (1983). Cultura Popular. In: Fávero, O. (org) Cultura Popular e a Educação Popular: memória dos anos 60: Edições Graal.

Konder, L. (1994). Flora Tristan: uma vida de mulher, uma paixão socialista: Relume Dumará.

Laraia, R. B. (1996). Cultura um conceito antropológico: Jorge Zahar Editor.

Lovato, F. L., Silva, B. T., Lourega, L. V., Alves, D. K. C., \& Muenchen, C. (2020). Análise da influência de Paulo Freire sobre as produções acadêmicas de pós-graduação da Universidade Federal de Santa Maria (2009-2018). Research, Society and Development, 9(2), e87922059. https://doi.org/10.33448/rsdv9i2.2059

Manfredi, S. M. (1984). A educação popular no Brasil: uma releitura a partir de Antonio Gramsci. In: Bezerra, A., \& Brandão, C. R. (Orgs.) A questão política da Educação Popular: Brasiliense, 1984.

Martins, C. E. (1983). A questão da cultura popular. In: Fávero, O. (org) Cultura Popular e a Educação Popular: memória dos anos 60: Edições Graal. 
Research, Society and Development, v. 10, n. 1, e54210112104, 2021

(CC BY 4.0) | ISSN 2525-3409 | DOI: http://dx.doi.org/10.33448/rsd-v10i1.12104

Mattos, S. M., Alencar, O. M., Pereira, F. H. L., \& Silva, M. R. F. da. (2020). Quando arte, ciência e política se encontram: uma reflexão sobre a experiência da "Vila dos poetas" como uma práxis Freireana. Research, Society and Development, 9(5), e147953322. https://doi.org/10.33448/rsd-v9i5.3322.

Muraro, R. M., \& Boff, L. (2002). Feminino e masculino: uma nova consciência para o encontro das diferenças: Sextante.

Pereira A. S. et al. (2018). Metodologia da pesquisa científica. UAB/NTE/UFSM.

Santos, B. S. (1995). Subjetividade, cidadania e emancipação. In: Santos, B. S. (Org.) Pela mão de Alice: o social e o político na pós-modernidade: Cortez.

Saviani, D. (2012). Pedagogia Histórico-Crítica. (Coleção educação contemporânea). (11a ed.), Autores Associados.

Scoguglia, A. C. (2003). A história das idéias de Paulo Freire e a atual crise dos paradigmas: Editora Universitária. 